\title{
The effect of Hepatitis C Virus infection on cardiovascular complications in end stage kidney disease patients on regular hemodialysis
}

\author{
Mohamed Salah Eldin Zaki
}

MD, Assistant Professor, Nephrology Department, National Institute of Urology and Nephrology, Cairo, Egypt

\section{Type of article: Original}

\begin{abstract}
Introduction: Cardiovascular complications are the most important cause of mortality in patients with ESKD, such as coronary artery disease, left ventricular hypertrophy, heart failure and arrhythmia. Other well-known risk factors, such as diabetes mellitus, hypertension and dyslipidemia are prevalent in ESKD, yet they are not sufficient enough to explain the high prevalence of cardiovascular mortality, hence searching for other hidden risk factors to explain this high prevalence is of an utmost importance. The aim of this study was to identify the exact mechanisms connecting HCV infection, chronic liver disease, and atherogenesis.

Methods: This case control study was done on 80 patients with chronic renal failure undergoing haemodialysis at Sheikh Zayed Specialized Hospital in Giza, Egypt in 2016. The participants were divided into four groups: a control group with HCV negative by PCR (20 patients), and three HCV Positive groups according to viral load by PCR: low, moderate and high viremia. Inclusion criteria were normal serum calcium (8.5-10.5 mg/dL), phosphorus $\leq 5 \mathrm{mg} / \mathrm{dL}, \mathrm{PTH} \leq 250 \mathrm{pg} / \mathrm{ml}, \mathrm{Hb} 10-12 \mathrm{~g} / \mathrm{dL}$, and duration of dialysis less than two years. Data were analyzed using Chi square, t-test, Mann-Whitney U test, ANOVA, and Spearman rank correlation coefficient.

Results: The study showed significant increase in LVM index in hemodialysis patients with high and moderate viremia compared to low viremia $(p<0.001)$ and to control group $(\mathrm{p}<0.001)$. Also, significant increase in end diastolic diameter in high and moderate viremia $(\mathrm{p}<0.001)$, significant difference in end systolic diameter in the high viremia group $(p<0.001)$, significant increase in the interventricular septal thickness $(p<0.002)$ and posterior wall thickness $(\mathrm{p}<0.002)$ among moderate viremia were determined.

Conclusion: $\mathrm{HCV}$ has a significant effect on the development of cardiovascular diseases in the general population, and in renal disease patients on the structural level.

Keywords: Hepatitis C, Viremia, End stage renal disease, Cardiovascular complication

\section{Introduction}

The hepatitis $\mathrm{C}$ virus (HCV) is a small, single-stranded, enveloped RNA virus of the Flaviviridae family, and can induce hepatitis C and hepatocellular carcinoma (HCC) and lymphomas in humans (1). Globally, around 130-150 million people have chronic hepatitis $\mathrm{C}$ infection (2). As in the general population, the prevalence of $\mathrm{HCV}$ among dialysis patients varies worldwide, ranging from as low as $1 \%$ to as high as over $70 \%$. Chronic inflammatory state due to viremia in those patients may increase cardiovascular risk. Oyake et al. measured aortic stiffness in 94 dialysis patients prospectively observing that $\mathrm{HCV}$ viremia was per se associated with high pulse-wave velocimeter measurements (3). They suggested that HCV plays an atherogenic role through the aggravation of individual components of the metabolic syndrome (insulin resistance, abdominal obesity, dyslipidemia, arterial hypertension, and hyperglycemia) (3,4). The precise mechanisms which connect HCV infection, chronic liver disease, and atherogenesis are still not fully understood, however, it is not unreasonable to assume that HCV may increase atherogenesis through a number of direct and indirect biological mechanisms (5).
\end{abstract}

\section{Corresponding author:}

Assistant Professor Dr. Mohamed Salah Zaki, Nephrology Department, National Institute of Urology and Nephrology, Cairo, Egypt. Tel.: +201114809999, Email: mszaki@yahoo.com

Received: November 02, 2016, Accepted: January 26, 2017, Published: February 2017

iThenticate screening: January 12, 2016 , English editing: February 04, 2017, Quality control: February 08, 2017

(C) 2017 The Authors. This is an open access article under the terms of the Creative Commons Attribution-NonCommercialNoDerivs License, which permits use and distribution in any medium, provided the original work is properly cited, the use is non-commercial and no modifications or adaptations are made. 


\section{Material and Methods}

This study was done on 80 patients with chronic renal failure undergoing haemodialysis in 2016. The patients were divided into four groups: A control group with HCV negative by PCR (20 patients), and three HCV Positive groups according to viral load by PCR: low, moderate and high viremia. Inclusion criteria were normal serum Calcium (8.5$10.5 \mathrm{mg} / \mathrm{dL}$ ), Phosphorus: $\leq 5 \mathrm{mg} / \mathrm{dL}, \mathrm{PTH} \leq 250 \mathrm{pg} / \mathrm{ml}, \mathrm{Hb}: 10-12 \mathrm{~g} / \mathrm{dL}$, and duration of dialysis less than two years. All patients underwent thorough history taking and a clinical examination, routine laboratory investigations, kidney function tests, and serum electrolytes. All the participants also underwent Quantitative PCR for hepatitis C levels. Viral RNA isolation was performed according to manufacturer's instructions (QIAamp Viral RNA Mini Kit \#52904 QIAGEN). In data collection, the assessment of parathormone level was also performed, as well as transthoracic echocardiography and calculation of left ventricular mass index (LVMI). We performed left ventricular mass index calculation: LVMI was determined by Devereux's formula $(1,3,4)$. Ultrasonographic studies on common carotid arteries were performed using a 7.5 $\mathrm{MHz}$ high resolution probe. IMT was defined as a low-level echoic grey band that does not project into arterial lumen, and was measured during end diastole as the distance from leading edge of the second echogenic line of the far walls of the initial tract of the internal carotid artery on both sides. Finally, data were analyzed by Statistical Analysis System (Version 6.03) using descriptive statistics, Chi square, t-test, MannWhitney U test, ANOVA, and Spearman rank correlation coefficient.

\section{Results}

Demographic features of different studied groups and the etiology of renal failure are presented in Tables 1 and 2 . The study showed no significant difference in the etiology of renal failure in different case and control groups $(p<0.09)$ (Table 2). The biochemical profile in different studied groups are also shown in Table 3. In our study, we noticed a significant increase in LVM index in hemodialysis patients with high and moderate viremia compared to low viremia $(\mathrm{p}<0.001)$ and to control group $(\mathrm{p}<0.001)$ (Table 4). Also, a significant increase in end diastolic diameter in high and moderate viremia in comparison to low viremia and the control group $(\mathrm{p}<0.001)$ were seen. End systolic diameter in the high viremia group significantly differs in comparison to the low, moderate viremia and the control group $(p<0.001)$ (Table 4). Also, interventricular septal thickness $(p<0.002)$ and posterior wall thickness $(p<0.002)$ significantly increase in moderate viremia versus low viremia and control group. However, our data showed no significant difference in carotid intimal thickness between the studied groups.

Table 1. Demographic features in different studied groups.

\begin{tabular}{|c|c|c|c|c|}
\hline \multirow[t]{2}{*}{ Variable } & \multirow{2}{*}{$\begin{array}{l}\text { Control } \\
(\mathrm{n}=20)\end{array}$} & \multicolumn{3}{|l|}{ HCV group } \\
\hline & & $\begin{array}{l}\text { Low viremia } \\
(\mathrm{n}=16)\end{array}$ & $\begin{array}{l}\text { Moderate viremia } \\
(\mathrm{n}=30)\end{array}$ & $\begin{array}{l}\text { High viremia } \\
(\mathrm{n}=14)\end{array}$ \\
\hline Age (year) & $56.45 \pm 8.85$ & $56.88 \pm 5.45$ & $55.67 \pm 11.23$ & $56.57 \pm 11.49$ \\
\hline Gender $(\mathrm{F} / \mathrm{M})$ & $4 / 16$ & $8 / 8$ & $8 / 22$ & $10 / 4$ \\
\hline Weight (kg.) & $72.62 \pm 14.14$ & $77.25 \pm 10.23$ & $73.60 \pm 13.31$ & $69.57 \pm 12.71$ \\
\hline Height $(\mathrm{m})$ & $1.65 \pm 0.06$ & $1.63 \pm 0.05$ & $1.66 \pm 0.08$ & $1.64 \pm 0.09$ \\
\hline BMI $\left(\mathrm{kg} / \mathrm{m}^{2}\right)$ & $26.6 \pm 4.7$ & $29.03 \pm 4.04$ & $26.67 \pm 4.54$ & $25.69 \pm 4.35$ \\
\hline $\begin{array}{l}\text { Duration of dialysis } \\
\text { (months) }\end{array}$ & $7.35 \pm 1.81$ & $6.88 \pm 1.31$ & $6.33 \pm 1.32$ & $7.14 \pm 1.70$ \\
\hline
\end{tabular}

Table 2. Etiology of renal failure in different studied groups

\begin{tabular}{|l|l|l|l|l|l|}
\hline \multirow{2}{*}{ Variable } & Control $(\mathrm{n}=20)$ & \multicolumn{2}{l}{ HCV group; $(\%)$} & \multirow{2}{*}{ p-value } \\
\cline { 3 - 5 } & & Low $(\mathrm{n}=16)$ & Moderate $(\mathrm{n}=30)$ & High $(\mathrm{n}=14)$ & \\
\hline Unknown & $4(20 \%)$ & $2(12.5 \%)$ & $6(20 \%)$ & $2(14.3 \%)$ & \multirow{2}{*}{0.091} \\
\hline DM & $7(35 \%)$ & $6(37.5 \%)$ & $8(26.7 \%)$ & $6(42.9 \%)$ & \\
\hline GN & $2(10 \%)$ & $2(12.5 \%)$ & $0(0 \%)$ & $4(28.6 \%)$ & \\
\hline HTN & $6(30 \%)$ & $6(37.5 \%)$ & $8(26.7 \%)$ & $2(14.3 \%)$ & \\
\cline { 1 - 4 } Polycystic kidney & $1(5 \%)$ & $0(0 \%)$ & $2(6.7 \%)$ & $0(0 \%)$ & \\
\hline Urology & $0(0 \%)$ & $0(0 \%)$ & $6(20 \%)$ & $0(0 \%)$ & \\
\hline
\end{tabular}


Table 3. Biochemical profile in different studied groups

\begin{tabular}{|l|l|l|l|l|l|}
\hline Variable & Control & Low viremia & Moderate viremia & High viremia & p-value \\
\hline $\mathrm{Ca}$ & $9.34 \pm 0.59$ & $9.34 \pm 0.56$ & $9.11 \pm 0.37$ & $9.44 \pm 0.64$ & 0.190 \\
\hline $\mathrm{Ph}$ & $4.32 \pm 1.05$ & $4.34 \pm 0.63$ & $4.21 \pm 0.73$ & $4.16 \pm 0.57$ & 0.890 \\
\hline SGOT & $20.05 \pm 9.26$ & $17.62 \pm 7.23$ & $15.4 \pm 5.87$ & $19.43 \pm 8.32$ & 0.149 \\
\hline SGPT & $28.3 \pm 10.33$ & $30.88 \pm 12.31$ & $28.0 \pm 18.22$ & $37.29 \pm 17.57$ & 0.278 \\
\hline ALP & $204.65 \pm 112.85$ & $153.38 \pm 80.91$ & $175.6 \pm 110.99$ & $209.14 \pm 95.01$ & 0.366 \\
\hline Urea & $127.35 \pm 15.80$ & $112.12 \pm 15.81$ & $119.67 \pm 22.38$ & $126.71 \pm 19.60$ & 0.082 \\
\hline Creatinine & $7.33 \pm 1.13$ & $7.5 \pm 0.68$ & $7.91 \pm 0.73$ & $7.73 \pm 1.06$ & 0.142 \\
\hline Hb & $10.78 \pm 0.43$ & $10.85 \pm 0.59$ & $10.69 \pm 0.52$ & $10.5 \pm 0.39$ & 0.251 \\
\hline
\end{tabular}

Table 4. Echocardiographic findings in different studied groups

\begin{tabular}{|l|l|l|l|l|l|}
\hline Variable & Control & Low viremia & Moderate viremia & High viremia & p-value \\
\hline LVMI & $43.94 \pm 10.93$ & $59.61 \pm 5.89^{\text {a }}$ & $63.52 \pm 6.76^{\text {a }}$ & $79.01 \pm 13.68^{\text {abc }}$ & 0.00 \\
\hline Ao & $28.7 \pm 4.94$ & $27.75 \pm 3.72$ & $28.8 \pm 5.11$ & $31.86 \pm 3.53$ & 0.089 \\
\hline LA & $37.5 \pm 7.04$ & $39.88 \pm 7.07$ & $39.4 \pm 6.43$ & $43.43 \pm 5.65$ & 0.088 \\
\hline EDD & $44.65 \pm 10.91$ & $51.88 \pm 4.43^{\text {a }}$ & $49.0 \pm 3.17^{\text {a }}$ & $59.29 \pm 5.59^{\text {abc }}$ & 0.001 \\
\hline ESD & $31.85 \pm 4.80$ & $33.25 \pm 4.16$ & $32.07 \pm 2.53$ & $40.0 \pm 7.19^{\text {abc }}$ & 0.001 \\
\hline FS & $37.95 \pm 10.68$ & $39.0 \pm 8.26$ & $37.87 \pm 7.37$ & $33.29 \pm 6.12$ & 0.250 \\
\hline EF & $64.35 \pm 9.35$ & $61.12 \pm 13.36$ & $63.4 \pm 11.19$ & $60.43 \pm 9.08$ & 0.679 \\
\hline IVSTd & $10.85 \pm 2.3$ & $11.25 \pm 1.98$ & $13.07 \pm 1.76^{\text {ab }}$ & $11.71 \pm 2.53^{\text {c }}$ & 0.002 \\
\hline PWTd & $11.0 \pm 2.25$ & $11.12 \pm 1.31$ & $12.67 \pm 1.27^{\text {ab }}$ & $12.0 \pm 1.84$ & 0.003 \\
\hline IVSTs & $15.0 \pm 2.47$ & $16.25 \pm 3.13$ & $18.07 \pm 1.84^{\text {ab }}$ & $16.71 \pm 2.27^{\text {a }}$ & 0.001 \\
\hline PWTs & $15.55 \pm 2.98$ & $16.62 \pm 2.13$ & $16.93 \pm 1.72$ & $16.86 \pm 1.61$ & 0.149 \\
\hline IMT & $1.08 \pm 0.17$ & $1.12 \pm 0.12$ & $1.09 \pm 0.22$ & $1.13 \pm 0.13$ & 0.784 \\
\hline PTH & $168.1 \pm 53.224$ & $187.12 \pm 53.29$ & $185.87 \pm 44.33$ & $172.29 \pm 29.97$ & 0.476 \\
\hline
\end{tabular}

Data are expressed as mean \pm SD or number (\%); a: $p<0.01$ relative to control group; $b: p<0.01$ relative to low group; c: $\mathrm{p}<0.01$ relative to moderate group

\section{Discussion}

The most significant causes of mortality in patients with ESKD are cardiovascular complications, such as coronary artery disease, heart failure, left ventricular hypertrophy and arrhythmia. Other well-known risk factors, such as diabetes mellitus, hypertension and dyslipidemia are prevalent in ESKD, yet they are not sufficient to explain the high prevalence of cardiovascular mortality, hence searching for other hidden risk factors to explain this high prevalence is of an utmost importance. A study by Omura et al. showed that at 12 months, mice that were transgenic for the HCV-core gene, developed ventricular dilatation, cardiac dysfunction, and myocardial fibrosis, comparable to the pathological presence seen in human dilated cardiomyopathy. Although HCV can cause a number of phenotypically dissimilar cardiomyopathies, mild inflammation with mononuclear cell infiltration has also been identified with HCV infection in humans. However, no lymphocytic infiltration was encountered in these HCV-core transgenic mice. Moreover, although typical characteristics of human hypertrophic cardiomyopathy are cardiomyocyte hypertrophy and disarray of the myofibers, the wall thickness of the HCV-core mice was not increased They also discovered enhancement of the expression of atrial and brain natriuretic polypeptides, and that activator protein-1 (AP-1) was activated in the heart, although, there was no activation of nuclear factor- $\mathrm{kB}$ (NF$\mathrm{\kappa B})$. According to the authors, the activation of myocardial AP-1 by HCV-core is a vital route toward cardiomyopathic changes, although whether blocking this pathway changes the disease phenotype, has not been shown. While in transgenic mice of HCV core protein, AP-1 is activated, (7) the latter affects the activation of AP-1 in human macrophages. Moreover, HCV core protein constrains AP-1, and stimulates c-Jun N-terminal kinase (JNK), extracellular signal-regulated kinase (ERK), and p38 mitogen-activated protein (MAP) kinase.

The study found no changes in NF-kB even though HCV core protein is known to activate NF-kB,21. Consequently, more studies are required to clarify the molecular pathogenetic changes experienced in HCV-core transgenic mice $(8,9)$. HCV hepatitis and cardiomyopathies pathogeneses are both compared. In HCV liver disease, the majority of patients develop chronic hepatitis and in later years, hepatic failure, liver cirrhosis or hepatocellular carcinoma. In the majority of patients with HCV heart disease, they develop chronic inflammation of the myocardium and, subsequently, dilated cardiomyopathy attributable to necrosis and loss of myocytes in later years. However, 
proliferative stimuli which is induced by HCV infection, can encourage myocyte hypertrophy and hypertrophic cardiomyopathy since myocytes do not replicate (10). Perplexing data have reported either normal or increased IMT, or normal or increased prevalence of carotid artery plaques in patients with a clinical diagnosis of HCV infection compared to general population. Keeping in mind the potential association between HCV infection and atherosclerotic disease, studies have highlighted that HCV seropositivity was an independent predictor of increased coronary atherosclerosis. A study found that G1 CHC patients had higher IMT compared to general population novel finding is the independent association of the presence of carotid plaques with severe hepatic fibrosis, after adjustment for age. Similarly, it was also found an independent association of IMT with low platelet count, an expression of more advanced fibrosis $(11,12)$. During a previous study, it was discovered that compared to the general population, G1 CHC patients had higher IMT. The finding shows the independent association of the presence of carotid plaques with severe hepatic fibrosis, following modifications for age. Similarly, an expression of more advanced fibrosis also found an independent association of IMT with low platelet count, $(11,12)$.Studies showed the presence of genomic and antigenomic HCV RNA strands within carotid plaque tissues in HCV+ve patients. Also, the proinflammatory and profibrogenic environment prompting fibrogenesis in the liver of HCVinfected patients could also be systemically activated, enhancing the development of atherosclerotic lesions, explaining the higher prevalence of carotid plaques in this subgroup of CHC patients. Furthermore, the profibrogenic and proinflammatory environment that prompts fibrogenesis in the liver of HCV-infected patients could also be systemically stimulated, increasing the progress of atherosclerotic lesions, which could account for the greater frequency of carotid plaques in this subgroup of CHC patients.

Patients with chronic hepatitis $\mathrm{C}$ had more hypertension, higher glycosylated hemoglobin level and a higher prevalence of metabolic syndrome. Patients with chronic hepatitis $\mathrm{C}$ had increased hs-CRP (high-sensitivity Creactive protein), sICAM-1 (soluble intercellular adhesion molecule-1), sVCAM-1 (soluble vascular cell adhesion molecule-1), and soluble E-selectin $(11,12)$. However our results show no direct association between viral load and atherosclerosis, probably due to the fluctuating levels of viremia in HCV infection, also, studies found lower levels of tPAI-1 (tissue-type plasminogen activator inhibitor-1), MMP9 (matrix metallopeptidase9), and MPO (myeloperoxidase) than their comparisons. Also, those with chronic hepatitis $\mathrm{C}$ had less dyslipidemia (including lower low-density lipoprotein and cholesterol/high-density lipoprotein ratio). In agreement with our data, Caliskan et al., stated that hepatitis c virus infection in hemodialysis patients is not associated with insulin resistance, inflammation and atherosclerosis. Since hemodialysis patients had a large number of cardiovascular risk factors, the effect of HCV infection could not be obvious (7). Aside from renal disease patients, overall 364,712 individuals who underwent investigation for any potential association between HCV infection and cardiovascular disorders in 31 studies have been reviewed in a systematic review, 6 out of 31 reviewed studies involving a cumulative population of $81,035(22.2 \%)$ subjects, reported a negative association between HCV infection and cardiovascular disorders. There were 2 prospective studies, both in favor of a significant relation between HCV infection and cardiovascular disease (13).

\section{Conclusions}

Our study showed that HCV have a significant effect on the development of cardiovascular diseases in the general population, and in renal disease patients on the structural level. There is not enough data available on the impact of HCV infection on development of atherosclerosis in the aorta in the general population, the only available studies are on kidney disease patients. Prospective cohort studies with more controlled conditions are needed to determine the amplitude of the problem.

\section{Acknowledgments:}

I would like to thank Sheikh Zayed Hospital management, my assistants and students.

\section{Conflict of Interest:}

There is no conflict of interest to be declared.

\section{Authors' contributions:}

All authors contributed to this project and article equally. All authors read and approved the final manuscript.

\section{References:}

1) Ferri $C$, Sebastiani M, Giuggioli D, Colaci M, Fallahi P, Piluso A, et al. Hepatitis C virus syndrome: A constellation of organ- and non-organ specific autoimmune disorders, B-cell non-Hodgkin's lymphoma, and 
cancer. World J Hepatol. 2015; 7(3): 327. doi: 10.4254/wjh.v7.i3.327. PMID: 25848462, PMCID: PMC4381161.

2) Fabrizi F. Hepatitis C Virus Infection and Dialysis: 2012 Update. International Scholarly Research Notices. 2012. doi: 10.5402/2013/159760.

3) Oyake N, Shimada T, Murakami Y, Ishibashi Y, Satoh H, Suzuki K, et al. Hepatitis c virus infection as a risk factor for increased aortic stiffness and cardiovascular events in dialysis patients. J Nephrol. 2008; 21(3): 345-53. PMID: 18587722.

4) Younossi ZM, Stepanova M, Nader F, Younossi Z, Elsheikh E. Associations of Chronic Hepatitis C With Metabolic and Cardiac outcomes. Aliment Pharmacol Ther. 2013; 37(6): 647-52. doi: 10.1111/apt.12234. PMID: 23384408.

5) Adinolfi LE, Zampino R, Restivo L, Lonardo A, Guerrera B, Marrone A, et al.. Chronic hepatitis $\mathrm{C}$ virus infection and atherosclerosis: Clinical impact and mechanisms. World J Gastroenterol. 2014 Apr 7;20(13):3410-7. doi: 10.3748/wjg.v20.i13.3410. PMID: 24707124, PMCID: PMC3974508

6) Devereux RB, Reichek N. Echocardiographic determination of left ventricular mass in man. Anatomic validation of the method. Circulation. 1977; 55: 613-8. PMID: 138494.

7) Caliskan Y, Oflaz H, Pusuroglu H, Boz H, Yazici H, Tamer S, et al. Hepatitis C virus infection in hemodialysis patients is not associated with insulin resistance, inflammation and atherosclerosis. Clin Nephrol. 2009; 71(2): 147-57. PMID: 19203507.

8) Omura T, Yoshiyama M, Hayashi T, Nishiguchi S, Kaito M, Horiike S, et al. Core protein of hepatitis C virus induces cardiomyopathy. Circ Res. 2005; 96: 148-50. doi: 10.1161/01.RES.0000154263.70223.13. PMID: 15618537.

9) De Simone G, Devereux RB, Daniels SR, Koren MJ, Meyer RA, Laragh JH. Effect of growth on variability of left ventricular mass: assessment of allometric signals in adults and children and their capacity to predict cardiovascular risk. J Am Coll Cardiol. 1995; 25: 1056-62. doi: 10.1016/0735-1097(94)00540-7. PMID: 7897116.

10) Matsumori A. Hepatitis C Virus Infection and Cardiomyopathies. Circulation Research. 2005; 96(2): 1447. doi: 10.1161/01.RES.0000156077.54903.67.

11) Petta S, Torres D, Fazio G, Cammà C, Cabibi D, Di Marco V, et al. Carotid Atherosclerosis and Chronic Hepatitis C: Prospective Study of Risk Associations. Hepatology. 2012; 55(5): 1317-23. doi: 10.1002/hep.25508. PMID: 22135089.

12) Roed T, Kristoffersen US, Knudsen A, Wiinberg N, Lebech AM, Almdal T, et al. Increased prevalence of coronary artery disease risk markers in patients with chronic hepatitis C--a cross-sectional study. Vasc Health Risk Manag. 2014; 10: 55-62. doi: 10.2147/VHRM.S53557. PMID: 24482574, PMCID: PMC3905100.

13) Karbasi Afshar R, Adibi P, Khedmat H, Jalali AR. How Hepatitis C Virus Infection Contributes to Cardiovascular Disease: A Systematic Review. International Journal of Travel Medicine \& Global Health. 2013; 1(2). 